Volume 14 - Número 2 - ago/dez de 2019

\title{
"FOTOGRAFANDO EM SALA DE AULA": UMA PROPOSTA DIDÁTICA PELO OLHAR DA MULTIMODALIDADE
}

\author{
"PHOTOGRAPHING IN THE CLASSROOM": A DIDACTIC PROPOSAL \\ THROUGH THE LOOK OF MULTIMODALITY
}

\begin{abstract}
Ana Cláudia Soares Pinto ${ }^{1}$
RESUMO: A sociedade contemporânea, de uma maneira geral, tem demonstrado grande preferência pela informação visual. Nas práticas sociais de leitura e de escrita, observamos que a imagem assume posição de destaque e como tal, elas nos comunicam muito sobre o mundo em que vivemos e sobre a cultura da qual fazemos parte. Diante desse cenário, apresentamos, neste trabalho, uma reflexão acerca de uma proposta didática com a fotografia pelo viés da multimodalidade. Dessa forma, objetivamos ressaltar a importância do contexto cultural para a construção do sentido do texto imagético e, consequentemente, para a formação crítica do aluno. Sob a orientação teórico-metodológica da multimodalidade e do contexto visual, representada principalmente pelos trabalhos de Almeida (2009), Dionísio (2005), Kress \& Van Leeuwen (1996), Rojo (2012) e Vieira (2007) analisamos trechos de um diário de campo da professora pesquisadora e produções textuais dos alunos visando observar aspectos das atividades realizadas que proporcionam uma visão de leitura e de produção respaldada pela multimodalidade. $\mathrm{O}$ estudo aponta para o desenvolvimento de uma consciência crítica por parte dos alunos, a partir da orientação multimodal e para a necessidade de reflexão acerca das práticas de sala de aula, tendo em vista a consideração de todas as formas de representação presentes na composição do texto, tão portadoras de significado quanto a linguagem verbal escrita.
\end{abstract}

PALAVRAS-CHAVE: Multimodalidade, Fotografia, Proposta didática.

ABSTRACT: In general, the contemporary society has shown a strong preference for visual information. In the social practices of reading and writing, we observe that the image takes a prominent position, all that surrounds us are images and as such, they communicate us a lot about the world in which we live and about the culture of which we are part. Faced with this scenario, we show in this project, a reflection about a didactic proposal with photography through multimodality bias. Thus, we aim to emphasize the importance of the cultural context for the construction of the meaning of the imagetic text and, consequently, for the critical formation of the student. Under the theoretical-methodological orientation of multimodality and the visual context, represented mainly by Almeida (2009), Dionísio (2005), Kress \& Van Leeuwen (1996), Rojo (2012) and Vieira (2007) we analyze excerpts from a field diary of the researcher and textual productions of the students to observe aspects of the activities performed that provide a vision of reading and production supported by multimodality. The study points to the development of critical awareness on the part of students from the multimodal orientation and the need for reflection on classroom practices in order to consider all forms of representation present in the composition of the text that are as meaningful as the written verbal language.

KEYWORDS: Multimodality, Photography, Didactic Proposal.

\section{Introdução}

Falar de imagem e texto verbal a partir de campos divergentes é tratar de maneira simplista a materialidade da linguagem, uma vez que as imagens mantêm uma relação cada vez mais próxima e de forma mais integrada com a modalidade escrita.

Nesse sentido, compreendemos que a contemporaneidade é caracterizada, entre outros fatores, pela visualidade em que está inserida e os signos verbais passaram a dividir espaço com os signos imagéticos, estabelecendo relações de sentido entre eles. Essas relações se constituem, de tal forma, que o significado de muitos textos só é construído com a presença de palavras e imagens simultaneamente.

\footnotetext{
${ }^{1}$ Doutora em Linguística pela Universidade Federal da Paraíba. Professora da Secretaria de Educação e Cultura/Campina Grande, PB - SEDUC/ PMCG. E-mail: claudianaspinto@gmail.com
} 
Volume 14 - Número 2 - ago/dez de 2019

A partir dessa realidade, é necessário superarmos a crença de que as modalidades escrita e falada da língua são as únicas formas de representação de informação existentes. Vieira (2007) afirma que "as práticas cotidianas opõem-se a essa tradição de valorização excessiva da língua escrita e oral e, pelo seu expressivo uso, testemunham em favor da imagem como a forma de comunicação mais eloquente da pós-modernidade" (VIEIRA, op. cit., p. 10). Para a autora, a imagem é uma forma de comunicação bastante significativa, na atualidade, basta observar que não apenas a cultura de massa tem mudado (layouts de páginas de revista, por exemplo), mas também documentos produzidos por instituições têm adquirido ilustrações coloridas e arranjos multimodais sofisticados que se fundem com o verbal e constroem novos sentidos discursivos.

Nessa perspectiva de reconhecimento dos diversos recursos semióticos para a comunicação em sociedade, entra em cena a multimodalidade discursiva, caracterizada pelo "uso integrado de diferentes recursos comunicativos, como a linguagem, imagem, som e música em textos multimodais e eventos comunicativos" (VAN LEEUWEN, 2011, p. 668).Com as facilidades do avanço tecnológico, o texto, no qual predomina um modo semiótico, não mais atende às necessidades da sociedade atual. A interação de linguagens variadas consubstanciadas em palavras, imagens, cores, gestos, entre outros é fundamental para a completude e compreensão do sentido por parte do leitor.

Assim, é muito importante que os gêneros multimodais estejam presentes no cotidiano de nossas escolas e universidades para que se possa contemplar "de forma consciente e sistemática a leitura de textos imagéticos" (ALMEIDA, 2011, p. 45). De fato, tais gêneros estão circulando nestes contextos, mas o que ainda falta é um letramento adequado por parte de quem os usa para melhor compreendê-los. Aos educadores apresenta-se o desafio de explorar, analisar e compreender textos multimodais e construir esta prática com seus alunos (CALLOW, 1999), especialmente por meio de textos multimodais autênticos, relevantes e presentes no cotidiano dos alunos.

Entendendo que a escola deve oferecer aos alunos subsídios básicos para estarem aptos a ler com completude e criticidade os diversos textos multimodais que estão presentes no nosso cotidiano, nos propomos a apresentar, neste trabalho, uma reflexão acerca de uma proposta didática com a fotografia pelo viés da multimodalidade. Dessa forma, temos como objetivos: (1) avaliar o desenvolvimento de uma proposta didática pela perspectiva multimodal; (2) ressaltar a importância da consideração do contexto cultural para a construção do sentido da fotografia; e (3) analisar a criticidade dos alunos a partir da composição visual das produções imagéticas.

Os dados considerados, neste estudo, referem-se a uma sequência de oito aulas dedicadas à leitura e à produção de fotografias e fazem parte de um trabalho maior desenvolvido em sala de aula sobre multimodalidade durante nossa pesquisa ${ }^{2}$ de Doutorado realizada em 2014.

Fundamentado nos estudos sobre multimodalidade e contexto visual, especialmente, nas contribuições de Almeida (2009),Kress\& Van Leeuwen(1996) e Rojo (2012) e nas concepções acerca da Linguística Aplicada(MOITALOPES, 2006; 2011), este trabalho apresenta três seções além desta introdução. Primeiramente, é apresentada uma caracterização geral do fenômeno da multimodalidade e suas implicações no processo de ensino/aprendizagem focalizando alguns conceitos que nos ajudarão no entendimento da proposta didática que nos propomos a realizar. Em seguida, descrevemos o contexto dos dados apresentados, interpretamos os resultados e, então, apresentamos algumas considerações finais trazendo para a discussão a necessidade de se contemplarem no trabalho de sala de aula propostas didáticas voltadas para a produção de sentidos a partir dos mais variados aspectos multimodais dos textos.

${ }^{2}$ Tal pesquisa foi produto da Tese "Um modelo Multimodal para a abordagem Didática de textos imagéticos: uma proposta para o Letramento Visual no Ensino de Língua Portuguesa" defendida em 2016 - PROLING/UFPB 
Volume 14 - Número 2 - ago/dez de 2019

\section{A multimodalidade}

A importância da noção de multimodalidade está cada vez mais evidente nas pesquisas com ênfase no texto e na produção de sentidos. De acordo coma perspectiva multimodal, não é possível ler textos de maneira eficiente considerando somente a linguagem escrita. Além desta, outros elementos representativos-diagramação/layout, formato, cor/cores, uso de imagensdesempenham importante papel constitutivo no significado do texto. Em virtude disso, produzir e entender textos multimodais, sobretudo na contemporaneidade em que os textos escritos passaram a empregar uma maior quantidade de elementos não verbais em suas construções, constitui tarefa de extrema relevância.

No arcabouço da Semiótica Social, a noção de multimodalidade das formas de representação que compõem uma mensagem foi introduzida por Kress \& Van Leeuwen (1996), buscando compreender todos os modos semióticos presentes na configuração do texto contemporâneo. Sendo assim, os autores propõem que se pense numa linguagem constituída como multimodal, em que o sentido advenha da relação textual estabelecida entre os diferentes modos utilizados para sua constituição e não que se pense isoladamente em cada um deles.

Vieira (2007, p.29) afirma que, nas práticas comunicativas do mundo contemporâneo, a imagem se impõe e invade todos os espaços de nossa vida de modo rápido e dominador, sendo difícil escaparmos da sedução com que ela nos atrai seja por meio do tamanho da imagem, pelo movimento ou pela cor ou beleza. Tal mudança demanda, pois, a necessidade de estabelecer um "novo olhar" para os textos contemporâneos, no sentido de reconhecer que nas práticas comunicativas da pós-modernidade prevalecem os textos multimodais, aqueles que empregam mais de um modo de representação da informação.

A multimodalidade encontra-se, portanto, nas múltiplas linguagens que utilizamos em situações de comunicação. Quando falamos, por exemplo, utilizamos, além da fala, gestos, movimentos corporais, entonações, etc. que vão ajudar a construir o sentido do texto que estamos elaborando. Na escrita, a multimodalidade ocorre quando temos o texto escrito incorporado a uma imagem ou a outra linguagem visual, como desenhos, fotografias, gráficos, cores, etc. Em relação à manifestação escrita, a própria disposição da escrita no papel já é considerada visual, conforme acentua Descardeci,

em uma página, além do código escrito, outras formas de representação como a diagramação da página (layout) a cor e a qualidade do papel, o formato e a cor (ou cores) das letras, a formatação, etc. interferem na mensagem a ser comunicada (2002,p.20-21).

Dessa forma, nas práticas sociais de linguagem, atualmente, nos é exigido ler muito mais do que o texto verbal. Exige-se que o processo de leitura de um texto multimodal ocorra de maneira integrada entre os elementos verbais e os recursos semióticos como a imagem, a cor, a tipografia, o som, dentre outros. Caso contrário, a compreensão da unidade global do texto será afetada. Veremos, a seguir, a abordagem de uma das contribuições teóricas acerca da sistematização do estudo do aparato visual, a Gramática do Design Visual (KRESS e van LEEUWEN, 1996).

\subsection{A Gramática do Design Visual (GDV)}

O lançamento da obra Reading Images: The Grammar of Visual Design dos autores Kress e Van Leeuwen (1996) foi, sem dúvida, um marco para os estudos sobre multimodalidade. Nessa obra, os autores argumentam sobre a importância e a necessidade de se desenvolver um método de análise que possibilite verificar como os recursos semióticos visuais reproduzem e constroem estruturas de significados sociais. 
Nesse sentido, os autores criticam as teorias semióticas tradicionais que atribuíam ao modo visual um papel meramente ilustrativo em relação ao texto verbal, inclusive contrariam a posição de Barthes (1977), que via a necessidade de uma dependência entre imagens e textos verbais para definir o significado visual ${ }^{3}$, e consideram que "o componente visual de um texto é uma mensagem independentemente organizada e estruturada, conectada com o texto verbal, mas de modo nenhum dependente dele" (KRESS e van LEEUWEN, 1996 p. 17)

A GDV apresenta padrões para a observação das imagens e de seus elementos, que passam a ser considerados como sintagmas visuais correspondentes aos que existem na sintaxe da linguagem escrita e oferece, ainda, uma descrição formal da estética das imagens que permite perceber os significados implicados na produção das estruturas imagéticas por seus produtores.

De acordo com Almeida (2009, p. 9), o que a gramática elaborada por Kress e van Leeuwen defende é

\begin{abstract}
a conscientização das imagens não como veículos neutros desprovidos de seu contexto social, político e cultural, mas enquanto códigos dotados de significado potencial, imbuídos de estruturas sintáticas próprias. Partem do pressuposto que assim como a linguagem verbal, a linguagem visual é dotada de uma sintaxe própria, na qual elementos se organizam em estruturas visuais para comunicar um todo coerente, até então associado exclusivamente à análise crítica de textos verbais. Estas estruturas podem incluir pessoas, lugares ou objetos inanimados na forma de participantes representados e estarem organizadas em diferentes níveis de complexidade.
\end{abstract}

A GDV apresenta-se, segundo seus autores, como ferramenta para análise visual com fins práticos e críticos. Práticos, no que concerne ao papel da comunicação visual como protagonistas em materiais pedagógicos e na democratização do design visual, antes tarefa exclusiva de especialistas. Críticos, como auxiliar na análise crítica do discurso, uma vez que a comunicação visual, e não somente o texto verbal, carrega mensagens que refletem ideologias e poder (KRESS e van LEEUWEN, op. cit, p.12). Com esse entendimento, advogamos a necessidade de fazer com que o conhecimento acerca da multimodalidade se faça presente no meio educacional, isto é, seja adaptado à realidade escolar de maneira didática buscando desenvolver e aprimorar as habilidades dos alunos em relação à competência textual-discursiva e ao senso crítico.

Fizemos menção às mudanças no cenário da linguagem e aos reflexos trazidos por essas mudanças para o texto contemporâneo e, assim, sentimos a necessidade de alterações também, nas práticas de ensino que devem pautar-se na preparação do aluno para lidar com a linguagem em suas diversas situações de uso e manifestações - atividades de linguagem - (BRONCKART, 2006). Em razão dessa realidade dos fenômenos postos pela vida social, alinhamos nossa discussão, na próxima subseção, às contribuições da Linguística Aplicada buscando compreender o que significa, hoje, produzir conhecimentos nesta área.

\title{
3 Orientações da Linguística Aplicada
}

No contexto pedagógico, entre outras vertentes, a Linguística Aplicada (LA) é chamada a colaborar no aperfeiçoamento do trabalho didático de sala de aula focalizando a linguagem como prática social e criando instrumentos tanto de trabalho, como de pesquisa que consigam definir e compreender melhor o processo de ensino-aprendizagem. Para tanto, a LA dialoga com teorias que têm em comum a perspectiva de compreender os tempos atuais e que abrem espaço às vozes que atuam, de fato, na vida social e que, por vezes, não são legitimadas.

\footnotetext{
${ }^{3}$ Barthes (1977) descreve três possibilidades de relação entre texto e imagem: ancoragem, quando o texto dá suporte à imagem; ilustração, quando a imagem dá apoio ao texto; "relay", quando outros significados são acrescentados para completar a mensagem (KRESS e van LEEUWEN, 1996 p.16).
} 
Volume 14 - Número 2 - ago/dez de 2019

Desse modo, o ensino-aprendizagem de línguas tem atuado de maneira a considerar problemas de uso da linguagem, socialmente relevantes e contextualizados, que abarcam questões de significação inerentes à linguagem e a sua vinculação com o contexto social: "A linguagem passou a ser um elemento crucial, tendo em vista a hiperssemiotização que experimentamos" (MOITA LOPES, 2011, p. 19). Logo, os problemas de linguagem presentes dentro da sala de aula propiciam ao linguista aplicado um olhar que oriente o ensinoaprendizagem da língua pela consideração das realidades sociais e por meio de um pensar sempre problematizador, não mais voltado, apenas, para as propriedades estruturais da língua, mas abarcando as propriedades de significação e compreensão que se caracterizam pela dinamicidade sígnica.

Essas características conduzem a LA a refletir e a questionar antigas práticas no espaço do ensino-aprendizagem de línguas, para incluir temas vinculados à vida contemporânea e presente nas inquietações dos sujeitos que os vivenciam atestando a relevância social da pesquisa. O que figura na discussão atual é quais discursos serão contemplados, que sujeitos serão pesquisados e que vozes serão ouvidas na prática discursiva do fazer científico. A relevância consiste, sobretudo, no sentido de trazer contribuições significativas para a realidade e nesse viés, uma das condições é trazer o sujeito para dentro do campo de investigação.

Seguindo essa orientação, no ensino-aprendizagem de língua materna, a proposta é inserir os alunos numa dinâmica de saber utilizar as diferentes linguagens para produzir, expressar e comunicar suas ideias, usufruir das produções culturais e interpretá-las, atendendo a diferentes intenções e situações de comunicação, ou seja, o ensino voltado para as práticas sociais de linguagem.

É no âmbito da compreensão desse novo paradigma linguístico que situamos a reflexão que fazemos neste artigo buscando enfatizar a importância de uma proposta didática pelo viés multimodal em sala de aula.

\section{Sobre a proposta didática}

A proposta didática aqui apresentada tem como objetivo promover o desenvolvimento das práticas de leitura e produção de textos multimodais oferecendo ao aluno condições de interagir mais criticamente com o texto multimodal e que seja norteadora do passo a passo das aulas. Para tanto, a configuração geral da proposta desdobrou-se em quatro módulos didáticos que contemplam duas dimensões: a dimensão contextual e a dimensão operacional.

Segundo Almeida (2011), é no entendimento da finalidade social dos textos e do seu contexto cultural associado às experiências da realidade cultural em que o leitor está inserido que as interpretações são construídas. Consoante com esse pensamento, a dimensão contextual contempla elementos sociais e culturais que são decisivos para a construção do sentido de um determinado texto imagético. A dimensão operacional, por sua vez, viabiliza a aprendizagem da metalinguagem necessária para se operacionalizar as análises e produções textuais imagéticas. 
Volume 14 - Número 2 - ago/dez de 2019

Quadro 1: Configuração da proposta didática

\begin{tabular}{|c|l|}
\hline \multicolumn{1}{|c|}{ Dimensões } & \multicolumn{1}{c|}{ Módulos } \\
\hline Contextual & $\begin{array}{l}\text { Módulo: Contato com o gênero } \\
\text { multimodal } \\
\text { Objetivo: } \\
\text { Observar o conhecimento e a vivência que os alunos tinham em relação } \\
\text { ao gênero trabalhado na realidade social em que vivem. } \\
\text { Módulo: Exploração do contexto social } \\
\text { Objetivo: } \\
\text { Refletir sobre as significações culturais e ideológicas agregadas aos } \\
\text { recursos imagéticos na constituição textual. }\end{array}$ \\
\hline $\begin{array}{l}\text { Módulo: Abordagem da metalinguagem } \\
\text { Objetivos: } \\
\text { Explorar, na composição visual, os elementos mais salientes; } \\
\text { Mobilizar conhecimentos acerca da utilização dos recursos imagéticos } \\
\text { na composição visual dos textos. }\end{array}$ \\
$\begin{array}{l}\text { Módulo: Produção de textos multimodais } \\
\text { Objetivos: } \\
\text { Desenvolver leituras mobilizando os aspectos imagéticos; } \\
\text { Produzir textos multimodais. }\end{array}$ \\
\hline
\end{tabular}

Fonte: Autoria própria

Para o delineamento da proposta didática utilizamos como princípio os postulados da sequência didática (SD) que defendem um conjunto sistemático de ações planejadas para o ensino de um determinado gênero textual (DOLZ, NOVERRAZ e SCHNEUWLY, 2004).

Também tivemos a preocupação com a modelização didática dos gêneros a serem trabalhados (cf. MACHADO e CRISTOVÃO, 2009), considerando o contexto de ensinoaprendizagem de Língua Portuguesa como língua materna. Ou seja, ao propor atividades que trabalhem o gênero multimodal para fins de ensino-aprendizagem, dando ênfase ao desenvolvimento de um leitor mais crítico e reflexivo e ao domínio, ao menos, das características gerais dos gêneros trabalhados, é preciso tratar o gênero como objeto de ensino para, a partir disso, organizá-lo em dimensões ensináveis.

\section{A sequência de aulas}

A sequência "Fotografando em sala de aula" foi desenvolvida com base na proposta didática do quadro 1 e tendo em vista aprimorar no aluno a capacidade de utilizar os elementos próprios do texto imagético e interagir por meio da fotografia. Os dados que consideramos a seguir referem-se a uma sequência de oito aulas realizadas em uma turma de $9^{\circ}$ ano - Ensino

\footnotetext{
${ }^{4}$ No âmbito desta proposta didática, ao utilizar o termo gênero multimodal estamos nos referindo, especificamente, à fotografia. Assinalamos que a natureza multimodal é inerente aos gêneros textuais falados ou escritos (DIONÍSIO, 2005),haja vista sua realização por meio de uma linguagem multissemiótica, na qual o verbal interage com a imagem e até mesmo com sons, gestos e movimentos que se entrelaçam para construir sentidos, portanto todo gênero é multimodal.
} 
Volume 14 - Número 2 - ago/dez de 2019

Fundamental II composta de 24 alunos. Assim, são participantes diretamente envolvidos os alunos dessa turma a e a professora titular.

Quadro 2: Síntese da sequência "Fotografando em sala de aula"

\begin{tabular}{|c|c|}
\hline \multicolumn{2}{|r|}{ Descrição das aulas realizadas a partir das notas de campo } \\
\hline Módulos & Descrição \\
\hline 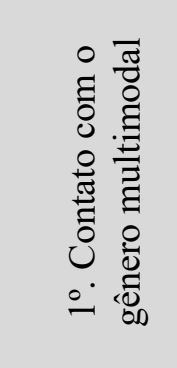 & $\begin{array}{l}\text { A professora apresenta em slides uma montagem com variadas fotografias de estilos e } \\
\text { épocas diferentes e instiga um debate sobre a presença da fotografia nos dias atuais. Os } \\
\text { alunos participam contando suas experiências como "fotógrafos." A professora explora } \\
\text { o assunto trazendo uma fotografia em forma de selfie e outra modificada por photoshop } \\
\text { que proporciona uma boa reflexão. A professora solicita que os alunos comentem, } \\
\text { oralmente e por escrito, sobre a fotografia do livro } \\
\text { didáticoqueabreaunidadeV,fazendorelaçõesentreavisãodemundodafotoeo } \\
\text { contexto cultural de cada um. }\end{array}$ \\
\hline 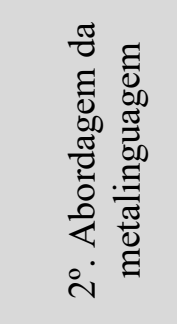 & $\begin{array}{l}\text { A professora retoma a atividade anterior (fotografia do livro didático) e explora } \\
\text { elementos/significados específicos da imagem como planos (geral, médio e corte em } \\
\text { close) e ângulos de visão (superior, inferior e nível do olhar). A professora projeta no } \\
\text { data show algumas fotos para ilustrar os elementos trabalhados e enfatiza usando o } \\
\text { quadro o tipo de relação que se estabelece com quem as vê. Os alunos fazem uma } \\
\text { atividade em dupla e, em sua maioria, se empolgam. A professora solicita que tragam } \\
\text { uma fotografia de casa para socializarem com a turma. }\end{array}$ \\
\hline 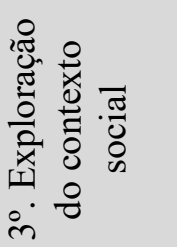 & $\begin{array}{l}\text { A professora expõe as fotografias solicitadas na aula anterior (apenas seis). A professora } \\
\text { faz uma reflexão sobre esse fato e informa que, organizados em dupla, irão fotografar a } \\
\text { escola. Os alunos aprovam a proposta e utilizam os celulares para fazerem as fotos. } \\
\text { Houve tumulto durante a atividade. A professora socializa as fotos tiradas por meio do } \\
\text { data show. Os alunos são chamados a explicar as decisões tomadas na hora de fotografar. }\end{array}$ \\
\hline 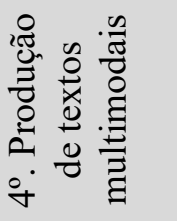 & $\begin{array}{l}\text { A professora distribui as fotografias tiradas na aula anterior e solicita aos alunos que } \\
\text { façam uma legenda para a foto que ficará exposta. Ela ressalta que observem por meio } \\
\text { da imagem a visão ou o "olhar da lente" de quem tirou a foto, a partir dos ângulos ou dos } \\
\text { planos utilizados. }\end{array}$ \\
\hline
\end{tabular}

Fonte: Autoria própria

Identificamos que nas atividades desenvolvidas no $1^{\circ}$ momento da proposta foram criadas condições para que os alunos, diante das fotografias apresentadas, pudessem se inserir naquele contexto falando de suas experiências pessoais com a fotografia enquanto uma prática social de sua realidade. Consideramos este momento inicial bastante enriquecedor para a reflexão do professor sobre as práticas sociais dos alunos em relação ao gênero trabalhado e também por favorecer a oportunidade de avaliação sobre os elementos nos quais, prioritariamente, os alunos se baseiam para ler ou refletir sobreas fotografias.

Ao se posicionarem sobre a selfie e sobre a utilização de photoshop nas fotografias, pudemos observar que os alunos demonstraram interagir com a era da imagem fotográfica que estamos vivendo ao associar, em geral, as imagens ao momento cultural da atualidade.

Percebemos que a dinâmica dada pela professora ao encontro inicial dessa sequência, a partir de uma montagem com fotos variadas garantiu, também, aos alunos a possibilidade de 
um olhar mais reflexivo - crítico e sensível acerca das fotografias, capacitando-os para questionarem a credibilidade das fotos, bem como para fazerem suas interpretações considerando a visão ou o recorte dado pelo fotógrafo.

Convém destacarmos, no segundo momento da proposta, o papel da metalinguagem para a interpretação do texto imagético, especificamente, a fotografia. A professora trabalhou com um dos planos de enquadramento da imagem - o plano aberto ou long shot conforme apresentado pela Gramática do Design Visual. A explanação criou um espaço favorável para explorar a relação virtual que se estabelece entre as pessoas fotografadas e os observadores. Verificamos na mediação da professora que ela expõe para os alunos o teor do novo conteúdo não se detendo, apenas, em classificar ou descrever o que seria o enquadramento de um plano aberto, mas contemplando a impressão codificada por meio desse plano como forma de proporcionar ao aluno condições de operacionalizar mais conscientemente interpretações e/ou produções fotográficas.

Pudemos perceber, também, que trabalhar com a linguagem específica do texto imagético, fez os alunos sentirem que, de fato, as estruturas visuais determinam significados importantes para a compreensão das imagens, e que precisam/merecem ser aprendidos (ALMEIDA, 2011). Naquele momento, especificamente, conhecimentos relacionados à imagem fotográfica.

$\mathrm{Na}$ sequência das aulas, $\left(3^{\circ}\right.$ momento $)$ a professora criou um espaço favorável para a contextualização das fotografias no tempo, bem como para a reflexão pessoal sobre os registros fotográficos. No cotidiano, fotografar tornou-se um hábito banal. A fotografia está ao alcance da grande maioria da população, haja vista a facilidade que se tem com os celulares de câmeras cada vez com maior qualidade. Por outro lado, os alunos evocaram nuances de uma ausência material de registro fotográfico nas famílias o que parece paradoxal ao cenário da atualidade.

Chama-nos atenção o fato de que a sociedade atual cada vez mais imagética e descartável, "é preciso digerir imagens rapidamente, consumir mensagens consubstanciadas em símbolos de internalização muitas vezes efềmera e de alta volatilidade" (OLIVEIRA, 2006, p.17), cria tendência que influencia as questões culturais (as famílias não têm mais fotografias em casa ${ }^{5}$ ) e o próprio relacionamento dos alunos com esse cenário.

O último momento da proposta foi dedicado ao trabalho de socialização e revisão (edição) de fotos feitas pelos alunos anteriormente a partir da seguinte orientação da professora: "Fazer uma fotografia de sua escola, destacando um espaço que você queira chamar atenção. Você deve escolher um problema que realmente o incomoda ou uma característica que muito lhe agrada. Lembre-se de que é sua escola vista pelo seu ângulo com o foco que você está querendo dar para ela".

Uma boa parte dos alunos declarou preferência por fotografar ambientes ou situações da escola que eles consideravam precários. Pareceu-nos uma forma de protesto, até ao falarem deixavam transparecer a indignação com algumas condições com as quais conviviam, como por exemplo, a falta de cobertura da quadra de esportes, um amontoado de cadeiras escolares jogadas, a sala de informática fechada, pichações nas paredes, entre outras. Os que registraram positividade escolheram o refeitório, grupos de amigos no intervalo, a sala da dentista, entre outros.

Verificamos que, ao fotografarem, os alunos construíram significações vinculadas à linguagem e a partir da avaliação estabelecida com aquele contexto social, ou seja, com a relação que estabelecem com a sua escola e que, intencionalmente, optaram por trazer uma materialização específica. Atitudes como essas ilustram bem o novo paradigma da LA que se ocupa de possibilidades de transformação da realidade, buscando propiciar aos participantes

\footnotetext{
${ }^{5}$ Esse fato foi observado após o cumprimento a uma solicitação da professora para que os alunos trouxessem
} fotografias da família. Apenas seis alunos trouxeram, os demais alegaram que não tinham fotografia em casa. 
novas formas de agir e de se constituir como cidadãos, questionando e reelaborando seus conhecimentos de mundo (MOITA LOPES, 2006).

$\mathrm{Na}$ fotografia a seguir, podemos observar essa forma de protesto ou a criticidade revelada na maneira como os alunos representaram a relação que têm com o meio em que vivem:

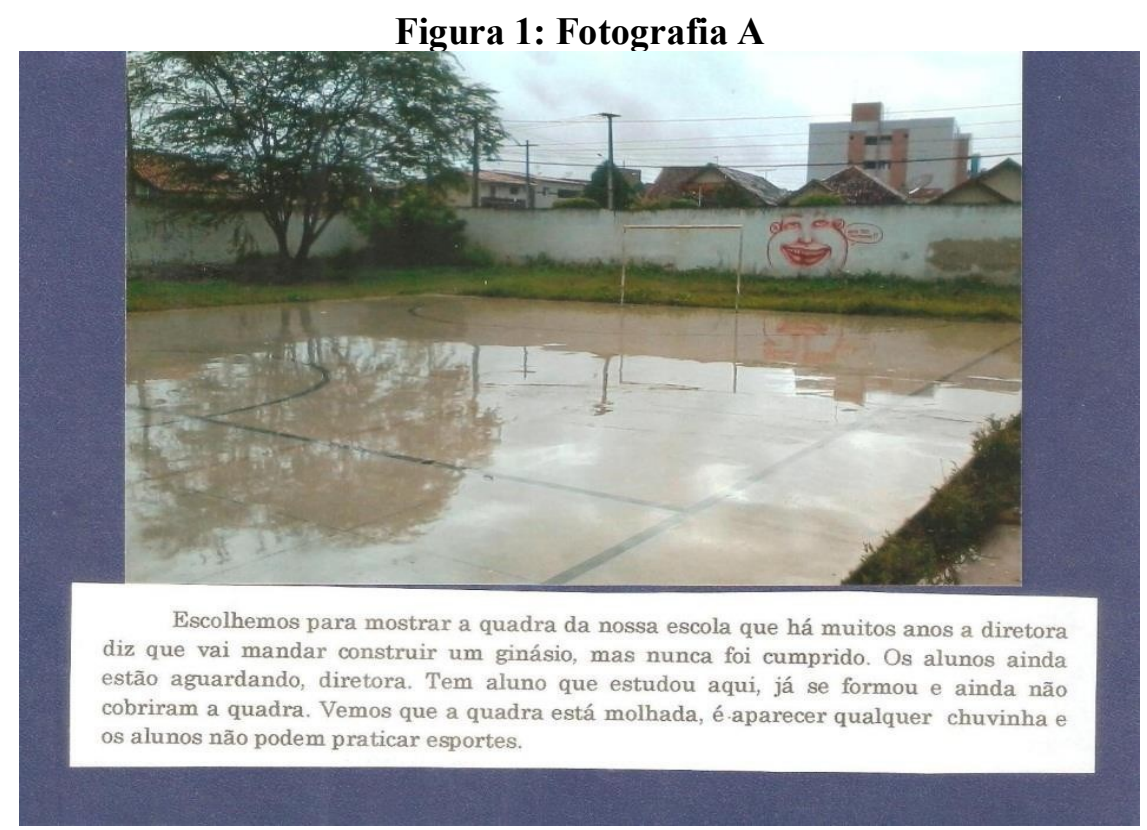

Fonte: Produção de fotografia realizada pelos alunos

A fotografia apresenta o registro de um determinado local da escola escolhido pelos alunos - a quadra de esportes. Identificamos, na imagem, as precárias condições em que a quadra encontra-se, além da não cobertura que é um problema destacado pelos alunos no texto verbal, observamos que está rodeada de vegetação denotando uma situação de abandono. Na participação dos alunos sobre suas próprias produções, comprovamos a postura engajada e crítica que tiveram diante dos espaços fotografados: professora essa quadra aqui tá igual promessa de político, há muito tempo a diretora diz que vai mandar construir um ginásio ma:: / tem aluno que estudou aqui já se formou e ainda não cobriram a quadra ((risos)). (Trecho de transcrição de aulas).

Assim, a imagem fotográfica feita pelos alunos vai além de uma fotografia qualquer. A partir da escolha por fotografar determinado espaço da escola, já detectamos implicações sobre os significados que tal espaço representa para o aluno, isto é, como os alunos percebem a realidade escolar, bem como os sentidos que atribuem a aspectos específicos da escola que frequentam.

Verificamos que, por meio dessa imagem, os alunos registraram a queixa ou a inquietação que sentem em relação àquela situação da quadra, bem como a denúncia de descaso e de omissão da administração escolar. Dessa forma, observamos um posicionamento que ultrapassa a materialidade da fotografia deixando "escapar" atitudes, valores e emoções dos alunos situados em outra materialidade associada às experiências da realidade sócio - cultural daquele determinado contexto. Percebemos, ainda, que a experiência com a imagem fotográfica revela uma motivação real para a produção dos alunos que se sentiram empoderados por poderem ser ouvidos e participar da produção do conhecimento sobre a realidade escolar a partir de seus pontos de vista.

A seguir, tomamos para análise mais uma fotografia nas quais verificamos indícios do propósito ou da intencionalidade dos alunos para fotografar: 
Volume 14 - Número 2 - ago/dez de 2019

Figura 2: Fotografia B

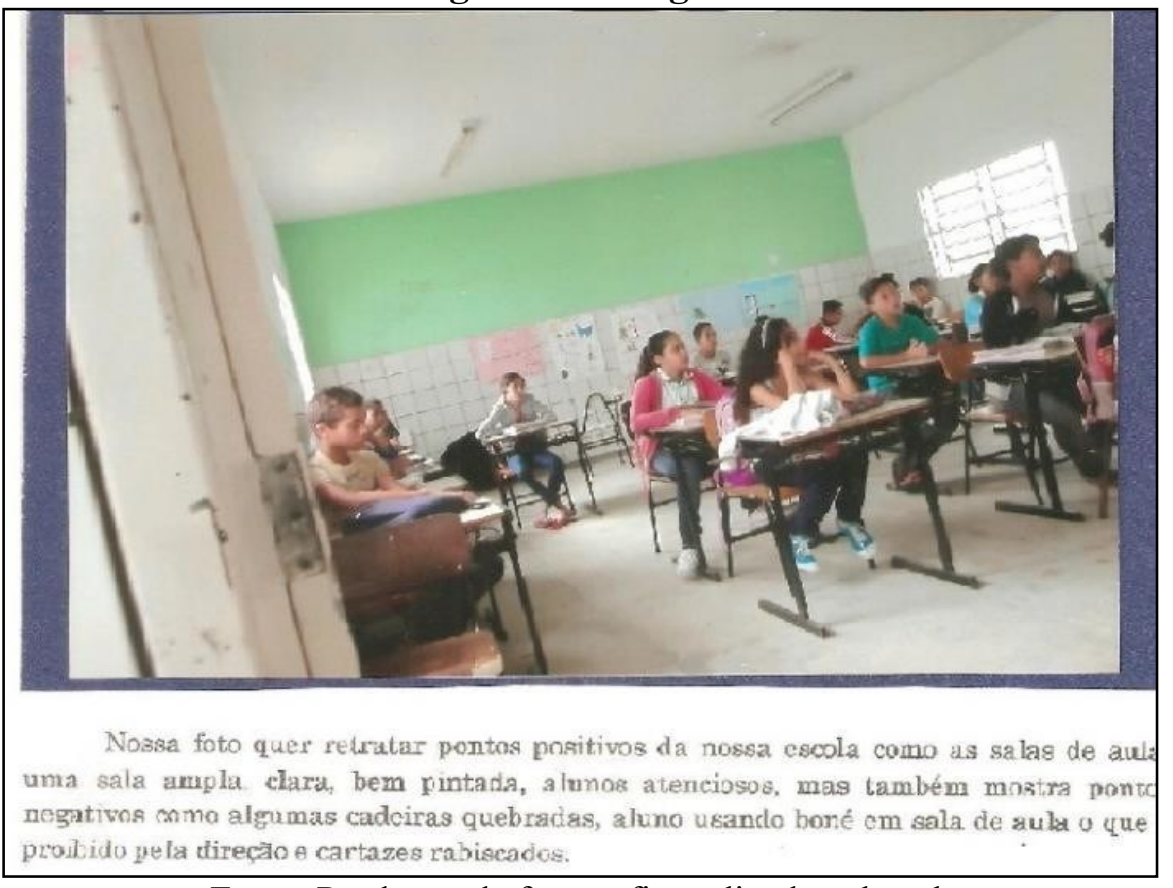

Fonte: Produção de fotografia realizada pelos alunos

Nas fotografias A e B, as decisões ou escolhas tomadas pelos alunos no momento da produção voltam-se para colocar em evidência um ambiente da escola por meio da apresentação de suas características positivas ou negativas. Para tanto, observamos que eles recorrem a determinadas estratégias de posicionamento dos participantes e de planos da imagem tendo em vista a possibilidade de favorecer o efeito de sentido desejado.

$\mathrm{Na}$ fotografia $\mathrm{B}$, os alunos se utilizam do plano aberto da imagem para representar uma sala de aula da escola com o objetivo de mostrar as boas condições físicas que as salas possuem. O plano aberto da imagem indica relações impessoais, mostra o integrante de modo distanciado, de corpo inteiro e podendo ocupar a metade ou mais da metade do enquadramento. A fotografia produzida pelos alunos mostra que, de fato, o que lhes interessava era mostrar o espaço e a acomodação das salas de aulas, por isso o enquadre dado por um plano aberto favoreceu essa visão geral e ampla da sala como um todo. Os alunos que aparecem na cena não demonstram nenhum envolvimento com o momento da fotografia - em sua maioria, estão voltados para um ponto específico da sala, provavelmente atentos ao professor. Tal postura contribui ainda mais para a construção de sentidos que os alunos produtores querem ressaltar de que o foco da informação é a sala de aula, em si, por isso o não envolvimento na cena.

Essa postura dos alunos de se utilizarem de elementos específicos da construção imagética, reconhecendo neles uma forma de materialização dos sentidos que querem construir nos textos, foi recorrente nas análises de suas produções. Nesse sentido, destacamos, como possibilidade real desse posicionamento, a sistematização de alguns conceitos da GDV explorados durante a realização do projeto didático que também fortaleceram atitudes mais imperativas dos alunos em relação às questões do letramento visual entendido como a habilidade de interpretar imagens e ser capaz de gerar conceitos e ideias a partir da produção de textos visuais (OLIVEIRA, 2007).

Algo muito interessante que conseguimos averiguar foi que as fotos não foram tiradas de qualquer lugar sem sentido, observamos que os alunos se identificaram com algo de real significado para eles a partir do contexto cultural.

O trabalho com aspectos da metalinguagem do texto imagético gerou empolgação nos alunos ao descobrirem visões de mundo desencadeadas por ângulos e planos da fotografia. Ao 
Volume 14 - Número 2 - ago/dez de 2019

fotografarem a escola, mostraram percepções diferentes e bastante autonomia no tocante ao olhar que queriam dar a foto. O viés crítico ficou evidente na maioria dos registros fotográficos.

\section{Considerações finais}

Neste trabalho, procuramos compreender o desenvolvimento de uma proposta didática com a fotografia pelo viés da multimodalidade possibilitando o contato com aspectos da produção fotográfica e com uma metalinguagem própria desse gênero contribuindo para o desenvolvimento da formação crítica dos alunos. Os dados demonstram o desenvolvimento da capacidade crítica acerca dos fatores socioculturais inerentes às imagens o que, em geral, dificilmente é abordado na esfera escolar do Ensino Fundamental. Isso porque o contexto de exposição visual ao qual estamos expostos favorece uma falsa familiaridade com os textos imagéticos fazendo com que os apreciemos sem refletir muito sobre eles, entendendo - os como se fossem "legíveis".

Voltando aos objetivos deste trabalho, a análise da sequência de aulas nos revela o desenvolvimento de uma prática de leitura e produção mais proficiente - consciente e crítica em relação ao seu uso, levando o aluno a posicionar-se e intervir no mundo através da materialização de um discurso mais questionador e socialmente engajado. Ou seja, a imagem fortaleceu a voz ao aluno, empoderando-o para atuar de forma crítica dentro do seu grupo social.

Face ao estudo realizado, verificamos que este possibilita uma reflexão bem mais ampla voltada para a discussão das noções de multimodalidade em contextos de ensino relacionando a leitura da linguagem verbal/escrita com a leitura da imagem. Pensamos que é a partir dessa interação premente entre a escrita e os recursos visuais na construção de sentidos dos textos que a escola pode promover atividades de leitura que favoreçam a formação de leitores mais proficientes. Pensar nessa perspectiva implica conceber o ensino da leitura de forma mais ampla, considerando as outras formas de representação presentes na composição do texto que são tão portadoras de significado quanto a linguagem verbal escrita.

\section{Referências}

ALMEIDA, D. B. L.de. Do texto às imagens: as novas fronteiras do letramento visual. In: PEREIRA, R. C.; ROCA, P. (Orgs.). Linguística Aplicada: um caminho com diferentes acessos. São Paulo: Editora Contexto, p. 173-202,2009.

. Pelos caminhos do letramento visual: Por uma proposta multimodal de leitura crítica de imagens. Linguagem em Foco. Revista do Programa de Pós-graduação em Linguística Aplicada da UECE, p. 43-63, 2011.

BRONCKART, J.P. Atividade de linguagem, discurso e desenvolvimento humano. Tradução Anna Raquel Machado e Maria de Lourdes M. Matencio. Campinas, SP: Mercado de Letras, 2006.

CALLOW, J. Reading the visual: an introduction. In Callow, J. (Ed.). Image matters: visual texts in the classroom. Newtown, NSW: Primary English Teaching Association (PETA), p. 113, 1999.

DESCARDECI, M. A. A. S Ler o mundo: um olhar através da Semiótica Social. Educação Temática Digital. Campinas, V.3, n.2, p. 19-26, 2002.

DIONÍSIO, A. P. Gêneros multimodais e multiletramento In: KARWOSKI, A.M; GAYDZECKA, K.S.B. (Orgs.) Gêneros textuais: reflexão e ensino. Palmas e União da Vitória, PR: Kaygangue, p 159-177,2005. 
Volume 14 - Número 2 - ago/dez de 2019

DOLZ, J. ; SCHNEUWLY, B . Gêneros Orais e escritos na escola. São Paulo: Mercado da Letras, 2004.

KRESS, G. R. e van LEEUWEN, T. Reading Images: a Grammar of Visual Design. Londres: Routledge, 1996.

MACHADO, A. R. et al.: Relações entre Linguagem e Trabalho Educacional: Novas Perspectivas e Métodos no Quadro do Interacionismo Sociodiscursivo. In: MACHADO, A. R.;CRISTOVÃO, V.L.L.; ABREU-TARDELLI, L.S. (Orgs.). Linguagem e Educação: O trabalho do professor em uma nova perspectiva. Campinas, SP: Mercado de letras, p.15-29, 2009.

MOITALOPES, L P. da. Da aplicação de Linguística à Linguística Aplicada Indisciplinar. In: PEREIRA, Regina Celi; ROCA, Pilar (Orgs.) Linguística aplicada: um caminho com diferentes acessos. São Paulo: Contexto 2011.

MOITA LOPES, L.P. da. Uma linguística aplicada mestiça e ideológica: interrogando o campo como linguista aplicado. In: (Org.) Por uma Linguística Aplicada Indisciplinar. São Paulo: Parábola, 2006.

OLIVEIRA, S. Explorando o texto visual em sala de aula. Trabalhos em Linguística Aplicada, v. 46, n. 2, pp. 181-197, 2007.

ROJO, R ; MOURA, E. (Org.). Multiletramentos na escola. São Paulo: Parábola Editorial, 2012.

van LEEUWEN, T. Multimodality. In: The Routledge Handbook of Applied Linguistics. London/New York: Routledge, p. 668-682, 2011.

VIEIRA, J. A. Novas perspectivas para o texto: uma visão multissemiótica. In: VIEIRA, J. A. [et al.] (Orgs.). Reflexões sobre a língua portuguesa: uma abordagem multimodal. Petrópolis, Rio de Janeiro: Vozes, p. 09-33, 2007. 